\title{
Résistance, existence, autorité
}

\section{(2) OpenEdition \\ Journals}

\section{Édition électronique}

URL : http://journals.openedition.org/conflits/18838

DOI : $10.4000 /$ conflits. 18838

ISSN : $1777-5345$

Éditeur :

CCLS - Centre d'études sur les conflits lilberté et sécurité, L'Harmattan

Édition imprimée

Date de publication : 8 juillet 2014

Pagination : 7-9

ISBN : 978-2-343-04155-1

ISSN : 1157-996X

\section{Référence électronique}

«Résistance, existence, autorité », Cultures \& Conflits [En ligne], 93 | printemps 2014, mis en ligne le 02 juillet 2015, consulté le 30 mars 2021. URL : http://journals.openedition.org/conflits/18838; DOI : https://doi.org/10.4000/conflits.18838 


\title{
Résistance, existence, autorité
}

\author{
Introduction
}

\section{Par le comité de rédaction de Cultures \& Conflits}

uelle unité peut exister entre des articles portant sur des sujets aussi
variés que des rébellions urbaines ou des entraves à l'action policière dans des quartiers périphériques français, l'expérience de sans-papiers latinoaméricains dans des chantiers du bâtiment à Barcelone, la vie dans des camps de réfugiés en Haïti après le séisme de 2010, l'usage de technologies d'espionnage des communications dans la Tunisie de Ben Ali et les stratégies de légitimation de l'OTAN lors de l'intervention militaire en Lybie en 2011 ? La diversité des thématiques, des approches, des terrains et des périodes plaide davantage pour une juxtaposition de ces textes que pour leur articulation. Et pourtant, les contributions rassemblées dans cette livraison de Cultures $\mathcal{E}$ Conflits partagent une perspective commune, que le titre "Résistance, existence, autorité » pourrait résumer. Toutes explorent en effet à leur manière les relations existantes entre des formes de domination et d'autorité ; les résistances qu'elles suscitent ; et la création d'identités et de subjectivités. Un triptyque dont des auteurs aussi différents que Max Weber, Michel Foucault, Edward P. Thompson, Pierre Bourdieu ou James C. Scott ont montré l'importance pour comprendre le monde social.

Les articles présentés ici fonctionnent par paires, selon l'angle de ce triptyque privilégié par les auteur(e)s. La première - résistance - rend compte des stratégies déployées par certaines fractions des jeunesses populaires pour contester l'autorité policière ou la mettre à distance. Abdellali Hajjat retrace ainsi les mobilisations des jeunes des Minguettes, en région lyonnaise, au début des années 1980, en les reliant aux transformations des modalités pratiques du contrôle policier tel qu'il pouvait s'exercer auparavant, lorsque le chantage aux expulsions constituait un élément central de régulation de l'ordre local. Marwan Mohammed, à partir d'une approche plus ethnographique, étudie quant à lui deux formes d'obstructions à l'activité policière. La première repose sur une hostilité diffuse des milieux populaires envers l'institution, analysable - dans la lignée des travaux de Richard Hoggart ${ }^{1}$ - par l'op- 
position nous / eux. La seconde apparaît plus instrumentale et vise à protéger les activités illicites (le commerce de stupéfiants notamment). Elle participe d'une tentative de certains acteurs juvéniles pour imposer un " pouvoir sur la rue ", dont l'auteur dresse les premiers contours.

Le couple de textes suivant - existence - explore les effets de différentes formes de domination sur l'existence quotidienne de populations particulièrement démunies. À partir d'un retour réflexif sur l'enquête qu'il a menée en travaillant pendant plus d'un an avec des maçons sud-américains à Barcelone, Yann Beldame étudie comment les dimensions de classe, de genre et de race affectent directement les relations qu'il a pu nouer avec ses collègues ouvriers et avec le chef de chantier. La présence inhabituelle d'un anthropologue français dans un univers ouvrier immigré fait en effet ressortir clairement les catégories et les hiérarchies de l'ordre social qu'ils ont intériorisé. Alice Corbet elle aussi anthropologue - analyse pour sa part les dynamiques très différentes de construction et de fonctionnement de deux camps de réfugiés construits en Haïti après le tremblement de terre de 2010. Le premier relève de l'action d'institutions internationales et d'organisations non gouvernementales, le second de logiques beaucoup plus informelles de peuplement et de regroupement. À partir de situations a priori similaires (l'urgence, le dénuement, la précarité existentielle), elle montre comment la structuration de ces camps débouche sur des modes d'organisations, de relations sociales et des fabrications d'identités véritablement différents.

Les deux derniers articles - autorité - portent sur des dispositifs de pouvoir. Marie Goupy s’intéresse à la surveillance des technologies de communication en Tunisie, sous le régime de Zine el-Abidine Ben Ali. À partir d'entretiens avec d'anciens responsables gouvernementaux, elle fait ressortir comment ces pratiques s'inscrivent dans un vaste éventail déployé par le régime pour neutraliser ses opposants. Mais elle montre également que la Tunisie peut se voir comme une sorte de laboratoire dans lequel ont pu s'expérimenter de nouvelles modalités de contrôle des populations, hybridant des ingénieurs et des policiers, ainsi que entreprises privées nationales et/ou internationales et des services de sécurité. En se déportant sur les régimes de justification, Julien Pomarède étudie les discours d'autorité employés par les militaires de l'OTAN pour justifier les frappes en Lybie en 2011. Suivant la perspective ouverte dans la revue par Didier Bigo, il explique que les stratégies de sécurisation qu'ils proposent passent nécessairement par des discours d'insécurisation 2 . La revendication d'opérations ciblées, à la violence létale contrôlée s'oppose ainsi à des massacres indiscriminés de civils, qui seraient commis par le régime de Mouammar Kadhafi. Au terme d'un renversement paradoxal, la

1. Hoggart R., La culture du pauvre, Paris, Éditions de minuit, 1970, pp. 117 et suiv.

2. Voir notamment "Sécurité et immigration : vers une gouvernementalité par l'inquiétude ?", Cultures E Conflits, 31-32, 1998, pp. 13-38 et "La mondialisation de l'(in)sécurité ? ", Cultures \& Conflits, 58, 2005, pp. 53-101. 
guerre, comme mode d'intervention sur des populations peut ainsi apparaître comme le meilleur moyen d'éviter les pertes de vie humaines dans ces populations.

Enfin, ce numéro de Cultures $\mathcal{E}$ Conflits a souhaité laisser une place à un Forum. Cette rubrique, inaugurée en 2011 sur le modèle de celle de la revue International Political Sociology souhaite présenter aux lecteurs des textes courts de collègues et de membres de la rédaction sur une question d'actualité peu ou mal traitée par les grands médias. Après «Les Roms comme prétexte : luttes autour des droits et de l'autorité » (n81-82, 2011) ; «Les Révolutions du "Printemps arabe" » $\left(\mathrm{n}^{\circ} 83,2011\right)$; «Le "printemps érable des étudiants québecois" " $\left(\mathrm{n}^{\circ} 87,2012\right)$; la revue à souhaité s'interroger sur « Tabou chimique et conflit en Syrie ». Christophe Wasinski, Barbara Delcourt, Samuel Longuet et Nizar Messari reviennent ainsi dans leurs contributions sur les différents enjeux, historiques, éthiques et techniques qui sous-tendent cette question sensible. 